\title{
PENERAPAN METODE KONSUMSI DENGAN PERAMALAN, EOQ, MMSL DAN ANALISIS ABC-VEN DALAM MANAJEMEN PERBEKALAN FARMASI DI RUMAH SAKIT PELAMONIA MAKASSAR
}

\author{
Veronica M.Dampung*), Alimin Maidin**), Ria Mardiana $\left.\mathbf{Y}^{* *}\right)$ \\ ${ }^{*}$ Bagian Farmasi Sekolah Tinggi Ilmu Kesehatan Pelamonia, Makassar \\ ${ }^{* *}$ Bagian Administrasi Rumah Sakit FKM Universitas Hasanuddin, Makassar
}

\author{
Alamat Korespondensi : \\ Veronica M.Dampung \\ J1. Cendrawasih No. 108 \\ HP : 0813-4265-4559 \\ E-Mail : veronicamd99@yahoo.com
}

\begin{abstract}
ABSTRAK
Kepmenkes RI No. 1197/Menkes /SK/ 2004 tentang Standar Pelayanan Farmasi di Rumah Sakit. Penelitian ini bertujuan untuk menentukan nilai EOQ, Safety Stock dan ROP untuk mencegah stagnasi dan stockout. Kemudian membandingkan nilai stok sebelum dan sesudah dilakukan simulasi perencanaan dan pengendalian perbekalan farmasi pada RS Pelamonia Makassar. Penelitian ini merupakan penelitian kualitatif dengan menggunakan teknik nonprobability sampling, yaitu snowball sampling dan purposive sampling.Sedangkan teknik analisis data yang digunakan adalah analisis data di lapangan (Model Miles and Huberman) serta analisis data selama di lapangan (Model Spradley) dengan memakai pendekatan analisis taksonomi dan komponensial.Hasil penelitian ini menemukan bahwa dengan adanya sistem perencanaan yang telah diperhitungkan dengan baik sebelumnya serta adanya pengendalian persediaan yang dilakukan akan lebih mengefisienkan pengelolaan perbekalan farmasi di apotik umum Instalasi Farmasi Rumah Sakit Pelamonia yang ditunjukkan dengan menurunnya nilai stok, angka TOR yang semakin tinggi dan ratio perbandingan stock persediaan dengan persediaan terpakai yang semakin kecil. Hasil ini memberikan gambaran bahwa Rumah Sakit Pelamonia khususnya apotik umum instalasi farmasi rumah sakit sebaiknya menggunakan perencanaan persediaan terpilih dan metode pengendalian persediaan terpilih untuk lebih mengefisienkan pengelolaan perbekalan farmasiapotik umum atau IFRS pada umumnya sehingga dapat mengurangi terjadinya angka stagnasi dan stockoutpada instalasi farmasi tersebut.
\end{abstract}

\section{Kata Kunci : Penerapan Metode Konsumsi dengan Peramalan, EOQ, MMSL dan Analisis ABC-VEN, stagnan dan stockout}

\section{PENDAHULUAN}

Rumah sakit (RS) adalah suatu organisasi yang unik dan komplek karena ia merupakan institusi yang padat karya, mempunyai sifat-sifat dan ciri serta fungsifungsi yang khusus dalam proses menghasilkan jasa medik dan mempunyai berbagai kelompok profesi dalam pelayanan penderita. Di samping melaksanakan fungsi pelayanan kesehatan masyarakat, RS juga mempunyai fungsi pendidikan dan penelitian. ( Muluk, 2007)

Instalasi farmasi merupakan salah satu revenue center utama di rumah sakit, mengingat lebih dari $90 \%$ pelayanan kesehatan di rumah sakit menggunakan perbekalan kesehatan (obat-obatan, bahan kimia, bahan radiologi, bahan alat kesehatan habis, alat kedokteran, dan gas medik) dan 40 - 50\% dari seluruh pemasukan rumah sakit berasal dari pengelolaan perbekalan farmasi. Di samping luasnya peran instalasi farmasi dalam kelancaran pelayanan kesehatan dan juga merupakan instalasi yang memberikan sumber pemasukan terbesar di rumah sakit. (Yusmainta, 2005)

Persediaan timbul karena tidak sinkronnya permintaan dengan penyediaan 
dan waktu yang digunakan untuk memproses bahan baku. Untuk menjaga keseimbangan permintaan dengan penyediaan bahan baku dan waktu proses diperlukan persediaan (Yamit, 2005). Menurut Miranda (2005), sekarang ini manajemen logistik yang efektif dikenal sebagai kunci elemen dalam pengembangan keuntungan dan hasil yang kompetitif dari perusahaan. Bersamaan dengan keefisienan dan keefektifan operasional, orientasi pemasaran menyediakan kesempatan memperoleh keuntungan yang kompetitif pada organisasi.

Ada beberapa faktor yang kemungkinan dapat berpengaruh terhadap terjadinya stagnasi dan stockout perbekalan farmasi yaitu perencanaan dan pengadaan, pengendalian persediaan, distribusi, formularium rumah sakit, hubungan/ komunikasi antara penyedia dan pemakai, komitmen,komitmen dari dokter, fasilitas peralatan dan informasi yang dibutuhkan (Quick, 1997).

Untuk menanggulangi permasalahan di atas maka diperlukan sistem Perencanaan atau Planning yang baik. Planning yang dimaksud adalah serangkaian aktivitas untuk menentukan jenis dan jumlah obat-obatan yang akan diadakan dalam pelayanan (Anshari, 2009).Beberapa cara yang dapat dilakukan rumah sakit untuk mengelola manajemen perbekalan farmasinya.Untuk memperoleh perhitungan kebutuhan obat yang rasional, dimana memperhitungan aspek efisensi yang disesuaikan dengan anggaran yang ada (Sulistyaningsih, 1999) .Manajemen perbekalan farmasi yang umum dipakai adalah analisis $\mathrm{ABC}$, analisis $\mathrm{ABC}$ indeks kritis, analisis VEN atau kombinasi analisis ABCVEN untuk menyusun prioritas kebutuhan dan penyesuaian kebutuhan dengan anggaran yang tersedia(Bowersox, 2002). Melalui pendekatan sistem seorang manajer akan mencapai suatu efek sinergistik dimana tindakan-tindakan berbagai bagian yang berbeda dari sistem tersebut jika dipersatukan akan lebih besar dibandingkan dengan jumlah dari bagian yang beraneka ragam.(Tampubolon, 2007)

Untuk permintaan yang berfluktuasi rumah sakit akan sulit untuk dapat memperkirakan dengan tepat jumlah dan jenis obat yang dibutuhkan oleh pasien dan harus disediakan oleh rumah sakit (Tjahyono,1998). Oleh karena itu rumah sakit dapat menyediakan safety stock (persediaan pengaman) untuk menghadapi ketidakpastian tersebut. Safety stock (persediaan pengaman) disediakan untuk menutupi fluktuasi yang tidak dapat diprediksikan dalam permintaan atau lead time (LT). Jika permintaan atau lead time (LT) lebih besar dibandingkan peramalan, maka stockout akan terjadi. Persediaan pengaman ini dilakukan untuk menghindari kemungkinan kekurangan persediaan.Tujuannya untuk melindungi hambatan dalam pengadaan atau penghantaran perbekalan farmasi dari distributor.Persediaan pengaman membantu untuk memaksimalkan customer service dengan mencoba melindungi dari ketidakpastian( Assauri,1984)

Untuk mengantisipasi kecendrungan rumah sakit melakukan pola pengadaan berlebih tetapi disisi lain dapat pula mengetahui berapa stok minimal sehingga tidak terjadi stock out, maka perlu dilakukan perhitungan nilai maksimal dan minimal stok dengan metode MMSL (Minimum-Maximum Stock Level) dengan mempertimbangkan stok pengaman (safety stock) sehingga titik pemesanan kembali (re order point) setiap item perbekalan farmasi dapat ditentukan. Semakin besar nilai safety stock (SS), semakin besar nilai re order point (ROP), semakin kecil kemungkinan stockout (Prihartini (2010). Metode EOQ adalah metode persediaan yang menentukan jumlah pemesanan paling ekonomis, yaitu jumlah pembelian barang yang dapat meminimalkan jumlah biaya pemeliharaan barang dari gudang dan biaya pemesanan setiap tahun.

Husnan dan Pudjiastuti (1994) menyatakan bahwa untuk menghitung efisiensi pengelolaan persediaan suatu obat digunakan rumus Turn Over Ratio (TOR) yakni HPP (Omzet selama satu tahun) dibagi dengan nilai persediaan akhir tahun. Semakin tinggi nilai TOR, maka semakin efisien pengelolaan persediaan barang/obat, jadi bila TOR rendah (kecil) berarti masih banyak stock yang belum terjual yang berakibat akan menghambat aliran kas sehingga berpengaruh terhadap keuntungan. Dimana nilai TOR yang ideal adalah $10-23$ kali pertahun (Indrawati dan Pudjaningsih 2001)

Menurut Heizer dan Render (1991), perbandingan nilai stock persediaan terhadap stock terpakai (pendapatan), idealnya sekecil mungkin. Angka perbandingan (ratio) ini menujukkan berapa lama modal kerja perusahaan tertanam dalam persediaan. Untuk 
barang yang perputarannya rendah, akan menunjukkan angka ratio yang tinggi, artinya modal perusahaan lama terpendam dalam persediaan dan begitu sebaliknya. Dimana menurut Prihartini (2010) perbandingan nilai stock persediaan terhadap stock terpakai (pendapatan) yang ideal adalah lebih kecil dari $1: 6$.

\section{METODE DAN BAHAN}

Penelitian ini dilaksanakan di Apotik umum Instalasi Farmasi Rumah Sakit Pelamonia Makassar pada bulan Maret - Mei 2014. Jenis data yang digunakan dalam penelitian ini adalah data berupa angka-angka yang diperoleh dari dokumen-dokumen rumah sakit yang berkaitan dengan penelitian yang dilakukan (data sekunder) serta hasil perhitungan/hasil analisis data. Sumber data yang digunakan dalam penelitian ini adalah data sekunder, yaitu data yang bersumber dari rumah sakit yang memiliki kaitan yang erat dengan penelitian yang dilakukan dan data primer yaitu data yang bersumber dari hasil wawancara terhadap beberapa tenaga kesehatan yang memberikan pelayanan kesehatan.

Dalam penelitian kualitatif tidak menggunakan istilah populasi, tetapi oleh Spradley dinamakan "social situation" atau situasi sosial yang terdiri atas tiga elemen yaitu : tempat (place), pelaku (actors) dan aktivitas (activity) yang berinteraksi secara sinergis. Dalam penelitian ini yang peneliti akan meneliti proses pengelolaan obat di Apotik umum Instalasi Farmasi Rumah Sakit Pelamonia, termasuk di dalamnya perencanaan obat, pengendalian persediaan (activity) yang dilakukan oleh tenaga farmasi serta dokter yang berkaitan dengan pengelolaan obat (actors) pada Instalasi Farmasi Rumah Sakit Pelamonia Makassar (Place). Untuk sampel berupa data yang digunakan hanyalah data terkait dengan pemakaian dan pengelolaan obat sedangkan untuk sampel berupa person atau orang yang diambil sebagai sampel adalah orang-orang yang berkompeten dan mengetahui pasti informasi yang dibutuhkan dalam pengambilan data untuk penelitian ini, seperti petugas di instalasi farmasi dan dokter spesialis yang menuliskan resep.

Data dikumpulkan dengan cara Metode dokumentasi yaitu merupakan metode pengumpulan data yang diperoleh dari sumber-sumber dokumen dan Metode wawancara (interview) yaitu merupakan metode yang digunakan untuk mengumpulkan data, khususnya mengidentifikasi indeks nilai kritis yang mungkin terjadi pada pengendalian persediaan obat. Wawancara ini dilakukan pada tenaga kesehatan yang memberikan pelayanan kesehatan terhadap pasien.

Teknik analisis data yang digunakan adalah analisis sebelum di lapangan, analisis data di lapangan (Model Miles and Huberman) serta analisis data selama di lapangan (Model Spradley) dengan memakai pendekatan analisis taksonomi dan komponensial. Dalam penelitian ini akan dihitung nilai EOQ, nilai stok maksimal-minimal (MMSL), stok pengaman (safety stock) dan titik pemesanan kembali ( Re Order Point) setiap item obat, dalam upaya untuk mencegah terjadinya stagnan dan stock out perbekalan farmasi yang telah terjadi selama tahun 2013. Selanjutnya dilakukan Perbandingan nilai omzet Sebelum dan Setelah penerapan Sistem Perencanaan Metode Konsumsi dengan peramalan dan Analisis ABC-VEN, Perbandingan Sisa Persediaan Obat Akhir Tahun Sebelum dan Setelah Menggunakan Sistem Pengendalian Persediaan (MMSL) dan Perbandingan TOR (Turn Over Ratio) dan Ratio Nilai Stock terhadap Persediaan Terpakai sebelum dan setelah penerapan Sistem Perencanaan Metode Konsumsi dengan peramalan 1 dan 3 bulan

\section{HASIL DAN PEMBAHASAN \\ Hasil Penelitian}

Tabel 1 menunjukkan bahwa dari 1.040 item perbekalan farmasi yang telah diolah berdasarkan analisis $\mathrm{ABC}$ investasi, ABC pemakaian dan Indeks kritis ABC, 260 item $(25 \%)$ perbekalan farmasi termasuk dalam kategori A, 596 item $(57,3 \%)$ termasuk dalam kategori B dan 184 item $(17,7 \%)$ termasuk dalam kategori $\mathrm{C}$.

Tabel 2 memperlihatkan bahwa dari 1.040 item perbekalan farmasi, 353 item $(33,9 \%)$ merupakan golongan Vital, 455 item $(43,8 \%)$ obat merupakan golongan Essensial dan 232 item $(22,3 \%)$ termasuk dalam golongan non-Essensial.

Tabel 3 menggambarkan dari 1.040 item perbekalan farmasi 111 item $(31,6 \%)$ termasuk dalam kategori VA, $210(59,8 \%)$ item termasuk dalam kategori VB, 30 item $(8,5 \%)$ termasuk dalam kategori VC, 139 item $(30,5 \%)$ termasuk dalam kategori EA, 216 
item $(47,4 \%)$ termasuk dalam kategori EB, 101 item $(22,1 \%)$ termasuk dalam kategori EC, 44 item $(18,9 \%)$ termasuk dalam kategori NA, 152 item $(65,2 \%)$ termasuk dalam kategori NB dan 37 item $(15,9 \%)$ termasuk dalam kategori $\mathrm{NC}$,

Tabel 4 menunjukkan bahwa jumlah total nilai pengadaan yang dikeluarkan selama tahun 2013 ditambah dengan sisa persediaan akhir (stock opname) tahun 2012 sebelum dilakukan penelitian adalah sebesar Rp. 3.420.754.133,-, sedangkan jumlah total nilai pengadaan yang akan dikeluarkan setelah dilakukan simulasi penelitian dengan stok pengaman $10 \%$ dan waktu tunggu 1 bulan adalah sebesar Rp. 3.046.457.729,- dan dengan simulasi penelitian dengan stok pengaman $10 \%$ dan waktu tunggu 3 bulan adalah sebesar Rp. 3.475.536.282,-

Tabel 5 menunjukkan bahwa sisa perbekalan farmasi pada akhir tahun (stock persediaan) sebelum dilakukan penelitian adalah sebesar Rp. 483,139,150,00 sedangkan sisa perbekalan farmasi pada akhir tahun (stock persediaan) setelah dilakukan simulasi penelitian dengan asumsi stok maksimal adalah sebesar Rp. 351,450,546,- dan stok minimal adalah sebesar Rp. 117,150,182,-

Tabel 6 menunjukkan bahwa TOR (Turn Over Ratio) sebelum dilakukan penelitian adalah sebesar 7,08 kali setahun sedangkan TOR (Turn Over Ratio) setelah dilakukan simulasi penelitian dengan LT 1 bulan adalah sebesar 10,37 kali setahun dan dengan LT 3 bulan adalah sebesar 11,70 kali setahun Sedangkan ratio perbandingan nilai stock persediaan terhadap persediaan terpakai sebelum dilakukan penelitian adalah sebesar 1 : 6 sedangkan ratio perbandingan nilai stock persediaan terhadap persediaan terpakai setelah dilakukan simulasi penelitian dengan LT 1 bulan adalah sebesar 1 : 9 dan dengan LT 3 bulan adalah sebesar 1:10.

\section{Pembahasan}

Data di atas menunjukkan terjadi peningkatan nilai TOR (Turn Over Ratio) setelah dilakukan simulasi penelitian dibandingkan sebelum simulasi penelitian. Hal ini menggambarkan bahwa efisiensi pengelolaan obat setelah dilakukan simulasi penelitian lebih baik bila dibandingkan dengan sebelum simulasi penelitian (Lihat Lampiran 14 untuk Lead Time 1 dan 3 bulan).
Sedangkan ratio nilai stock persediaan terhadap persediaan terpakai setelah dilakukan penelitian lebih kecil bila dibandingkan dengan sebelum dilakukan simulasi penelitian. Hal ini menunjukkan bahwa perbekalan farmasi yang stagnan menjadi semakin berkurang, dengan demikian modal Rumah Sakit juga dengan sendirinya tidak lama terpendam sebagai persediaan pada saat setelah dilakukan simulasi penelitian.

Husnan dan Pudjiastuti (1994) menyatakan bahwa untuk menghitung efisiensi pengelolaan persediaan suatu obat digunakan rumus Turnover Ratio (TOR) yakni HPP (Omzet selama satu tahun) dibagi dengan nilai persediaan akhir tahun. Semakin tinggi nilai TOR, maka semakin efisien pengelolaan persediaan barang/obat, jadi bila TOR rendah (kecil) berarti masih banyak stock yang belum terjual yang berakibat akan menghambat aliran kas sehingga berpengaruh terhadap keuntungan.

Pada ratio perbandingan nilai stock terhadap persediaan sebelum dilakukan simulasi penelitian lebih besar bila di bandingkan dengan ratio nilai stock terhadap persediaan setelah dilakukan simulasi penelitian. Hal ini menunjukkan bahwa modal kerja perusahaan lebih lama tertanam dalam persediaan pada sebelum dilakukan penelitian dibandingkan setelah dilakukan penelitian (perputarannya rendah).

Menurut Heizer dan Render (1991), perbandingan nilai stock persediaan terhadap stock terpakai (pendapatan), idealnya sekecil mungkin. Angka perbandingan (ratio) ini menujukkan berapa lama modal kerja perusahaan tertanam dalam persediaan. Untuk barang yang perputarannya rendah, akan menunjukkan angka ratio yang tinggi, artinya modal perusahaan lama terpendam dalam persediaan dan begitu sebaliknya.

Hal ini menjelaskan bahwa efisiensi pengelolaan obat dengan menggunakan sistem perencanaan metode konsumsi dengan peramalan dan pengendalian persediaan menggunakan system MMSL-EOQ dengan analisis ABC-VEN lebih efisien.

\section{PENUTUP}

Kesimpulan

Dengan menggunakan metode EOQ (Economic Order Quantity), dan menghitung safety stock dan jumlah pemesanan kembali 
atau ROP ( Re Order Point) setiap item perbekalan farmasi, dapat diperoleh efisiensi dalam manajemen perbekalan farmasi. Nilai omzet perbekalan farmasi di Apotik umum Rumah Sakit Pelamonia Makassar sesudah penerapan perencanaan metode konsumsi dengan peramalan menggunakan Lead Time 1 bulan dan Analisis ABC-VEN menjadi lebih kecil daripada sebelum penelitian, sebaliknya setelah menggunakan Lead Time 3 bulan dan Analisis ABC-VEN menjadi lebih besar daripada sebelum penelitian. Nilai stok akhir tahun perbekalan farmasi di Apotik umum Rumah Sakit Pelamonia Makassar sesudah penerapan pengendalian dengan menggunakan metode MMSL (Maksimum Minimum Stock Level) menjadi lebih kecil jika dibandingkan sebelum penerapan pengendalian dengan menggunakan metode MMSL (Maksimum Minimum Stock Level). Nilai TOR (Turn Over Ratio) lebih tinggi setelah dilakukan simulasi penerapan perencanaan metode konsumsi dengan peramalan (forcasting) dibandingkan dengan sebelum dilakukan simulasi penelitian. Ratio nilai stock persediaan terhadap persediaan terpakai setelah dilakukan simulasi penelitian menjadi lebih kecil jika dibandingkan sebelum dilakukan simulasi penelitian.

\section{Saran}

Disarankan agar Rumah Sakit pelamonia untuk membentuk suatu tim perencanaan pengadaan khusus bahan medis dan menggunakan system perencanaan metode konsumsi serta menggunakan sistem pengendalian persediaan yaitu MMSL dan EOQ untuk lebih menghemat biaya.

\section{DAFTAR PUSTAKA}

Anshari, Muhammad., (2009). Aplikasi Manajemen Pengelolaan Obat dan Makanan, Jogjakarta : Nuha Medika.

Assauri, Sofjan, (1984). Teknik dan Metode Peramalan: Penerapannya dalam bidang Ekonomi dan Dunia Usaha, Edisi 1, Jakarta : Lembaga Penerbit Fakultas Ekonomi Universitas Indonesia.

Bowersox, Donald J, (2002), Manajemen Logistik, Integrasi Sistem Manajemen Distribusi Fisik dan Manajerial Material, Alih bahasa oleh A.
Hasyim Ali, Drs, Cetakan ke -4 PT.Bumi Aksara, Jakarta.

Heizer J. dan Render B. (1991), Production and Operations Management, Second Edition, Allyn and Bacon, Boston.

Husnan S. Dan Pudjiastuti E., (1994. DasarDasar Manajemen Keuangan, Unit Pengembangan Pendidikan Akademi Manajemen Perusahaan, Yogyakarta : Yayasan Keluarga Pahlawan Nasional

Kepmenkes RI No. 1197/Menkes SK/2004 tentang Standar PelayananFarmasi di Rumah Sakit (20 Agustus 2005, Http:/www.depkes.go.id/downloads/st andar\%20\%20RS\% $201197 \quad 204$ 45.pdf).

Miranda, S. T., A. W., (2005). Manajemen Logistik dan Supply Chain Management, Jakarta : Harvarindo.

Muluk, K. Budaya Organisasi Pelayanan Publik (Kasus pada Rumah Sakit X di Malang) diambil dari (http://publik.brawijaya.ac.id/simple/ us/jurnal/pdffile/Budayaorganisasi. Tanggal 7 september 2007)

Prihartini A. Anwar, (2010), Analisis Faktor Penyebab Stagnasi Obat Pada Instalasi Farmasi Rumah Sakit Stella Maris Makassar". (Tesis)

Indrawati, C. S. Suryawati, S. Pudjaningsih, (2001), Analisis Pengelolaan Obat Di Rumah Sakit Umum Daerah Wates. Jurnal Manajemen Pelayanan Kesehatan.

Quick JD. (1997). Managing Drug Supply : The Selection, procurement, distribution and use of pharmaceuticals, Second Edition. Connecticut : Kumarin Press Inc.

Sulistyaningsih, L. Suryawati, S., (1999), Evaluasi Manajemen Obat di RSUD Wangaya Kotamadya Dati II Denpasar, Jurnal Manajemen Pelayanan Kesehatan,

Tampubolon, M. Silabon, P., (2004). Penerapan dan Pendekatan Teori Sistem : Studi Kasus Universitas HKBP Nomensen.. Diambil dari 
http://www.library.usu.ac.id/downloa $\mathrm{d} / \mathrm{ft} /$ sipil-muslim3.pdf.

Tjahjono B., (1998). Manajemen Logistik dan Obat, Program Pascasarjana Universitas Airlangga, Surabaya.

Trisnantoro, L. (2005), Aspek Strategis Manajemen Rumah Sakit Antara Misi Sosial dan Tekanan Pasar. Andi.Yogyakarta.
Yamit Z, (2003), Manajemen Persediaan. Yogyakarta : EKONISIA

Yusmainita, (2002), Pemberdayaan Instalasi Farmasi Rumah Sakit Pemerintah (Bagian I), Medika, No. 12 tahun ke XXVIII, Desember 2002, ISSN 0216-0910 
Tabel 1. Rekap nilai EOQ, Safety Stock dan ROP

\begin{tabular}{|c|c|c|c|c|c|c|c|}
\hline \multirow[b]{2}{*}{ NO } & \multicolumn{5}{|c|}{ EOQ } & \multirow[b]{2}{*}{$\begin{array}{c}\text { Safety } \\
\text { Stock(Rata- } \\
\text { Rata) }\end{array}$} & \multirow[b]{2}{*}{$\begin{array}{c}\text { ROP } \\
\text { (Rata-rata) }\end{array}$} \\
\hline & $\begin{array}{c}\text { Frekuensi } \\
\text { Pesan(X) }\end{array}$ & $\begin{array}{c}\text { Jumlah } \\
\text { Kebutuhan / } \\
\text { tahun }\end{array}$ & $\begin{array}{c}\text { Rata-rata } \\
\text { Jumlah } \\
\text { Pesan } \\
\text { (unit)/X }\end{array}$ & $\begin{array}{c}\text { Jumlah } \\
\text { Item }\end{array}$ & $\%$ & & \\
\hline 1 & 1 & $1-17$ & 9 & 162 & 15.58 & 0 & 1 \\
\hline 2 & 2 & $18-52$ & 35 & 239 & 22.98 & 1 & 3 \\
\hline 3 & 3 & $53-104$ & 79 & 167 & 16.06 & 3 & 6 \\
\hline 4 & 4 & $105-174$ & 140 & 150 & 14.42 & 5 & 11 \\
\hline 5 & 5 & $175-260$ & 218 & 101 & 9.71 & 8 & 17 \\
\hline 6 & 6 & $261-365$ & 313 & 80 & 7.69 & 11 & 23 \\
\hline 7 & 7 & $366-486$ & 426 & 40 & 3.85 & 15 & 32 \\
\hline 8 & 8 & $487-626$ & 557 & 20 & 1.92 & 20 & 43 \\
\hline 9 & 9 & $627-782$ & 705 & 22 & 2.12 & 25 & 54 \\
\hline 10 & 10 & $783-956$ & 870 & 16 & 1.54 & 31 & 67 \\
\hline 11 & 11 & $957-1.147$ & 1052 & 13 & 1.25 & 38 & 82 \\
\hline \multirow[t]{2}{*}{12} & 12 & $1.148-4.101$ & 2625 & 30 & 2.88 & 72 & 155 \\
\hline & & & & 1.040 & 100.00 & & \\
\hline
\end{tabular}

Sumber : Data Primer

Tabel 2. Hasil Analisis ABC Total

\begin{tabular}{cccc}
\hline NO & Kategori & Jumlah Item Perbekalan farmasi & Persentase \\
\hline \hline $\mathbf{1 .}$ & $\mathrm{A}$ & 260 & $25,0 \%$ \\
$\mathbf{2 .}$ & $\mathrm{B}$ & 596 & $57,3 \%$ \\
$\mathbf{3 .}$ & $\mathrm{C}$ & 184 & $17,7 \%$ \\
\hline \hline & Jumlah Total & $\mathbf{1 . 0 4 0} \%$ \\
\hline & Sumber : Data Primer & \\
& & Tabel 6.Hasil Analisis VEN & \\
\hline NO & Kategori & Jumlah Item Obat & Persentase \\
\hline $\mathbf{1}$ & $\mathrm{V}$ & 353 & $33,9 \%$ \\
$\mathbf{2}$ & $\mathrm{E}$ & 455 & $43,8 \%$ \\
$\mathbf{3}$ & $\mathrm{N}$ & 232 & $22,3 \%$ \\
\hline & Jumlah Total & $\mathbf{1 . 0 4 0}$ & $\mathbf{1 0 0} \%$ \\
\hline
\end{tabular}

Sumber : Data Primer 
Tabel 3.Hasil Analisis ABC - VEN

\begin{tabular}{|c|c|c|c|c|c|c|c|c|c|}
\hline \multirow[t]{2}{*}{ NO } & \multicolumn{7}{|c|}{ ANALISIS VEN } & \multicolumn{2}{|c|}{ Jumlah Total } \\
\hline & $\begin{array}{c}\text { ANALIS } \\
\text { IS ABC }\end{array}$ & & $\mathbf{V}$ & & $\mathbf{E}$ & & $\mathbf{N}$ & & \\
\hline 1 & $\overline{\mathbf{A}}$ & 111 & $31,6 \%$ & 139 & $30,5 \%$ & 44 & $18,9 \%$ & 294 & $28,3 \%$ \\
\hline 2 & B & 210 & $59,8 \%$ & 216 & $47,4 \%$ & 152 & $65,2 \%$ & 578 & $55,6 \%$ \\
\hline \multirow[t]{2}{*}{3} & $\mathbf{C}$ & 30 & $8,5 \%$ & 101 & $22,1 \%$ & 37 & $15,9 \%$ & 168 & $16,2 \%$ \\
\hline & Jumlah & 351 & $100 \%$ & 456 & $100 \%$ & 233 & $100 \%$ & 1.040 & $100 \%$ \\
\hline
\end{tabular}

Sumber : Data Primer

Tabel 4. Perbandingan nilai omzet Sebelum dan Setelah penerapan Sistem Perencanaan Metode Konsumsi dengan peramalan dan Analisis ABC-VEN

\begin{tabular}{ccc}
\hline Total Harga Pengadaan Obat & Total Harga Pengadaan & Total Harga Pengadaan \\
Sebelum Menggunakan & Obat Setelah Menggunakan & Obat Setelah \\
Metode Konsumsi + An. & Metode Konsumsi LT 1 & Menggunakan Metode \\
ABC-VEN & dengan & Konsumsi LT 3 dengan \\
& AN. ABC-VEN & AN. ABC-VEN \\
\hline Rp. 3.420.754.133,- & Rp. 3.046.457.729,- & Rp. 3.475.536.282,-
\end{tabular}

Sumber : Data Primer

Tabel 5.Perbandingan Sisa Persediaan Obat Akhir Tahun Sebelum dan Setelah Menggunakan Sistem Pengendalian Persediaan (MMSL)

\begin{tabular}{|c|c|c|}
\hline $\begin{array}{c}\text { Sisa stok Sebelum } \\
\text { Menggunakan MMSL }\end{array}$ & $\begin{array}{l}\text { Sisa stok Setelah Menggunakan } \\
\text { MMSL } \quad \text { (stok maksimal) }\end{array}$ & $\begin{array}{c}\text { Sisa stok Setelah } \\
\text { Menggunakan MMSL ( } \\
\text { stok minimal) }\end{array}$ \\
\hline Rp. 483,139,150,- & Rp. 351,450,546,- & Rp. 117,150,182,- \\
\hline
\end{tabular}

Tabel 6. Perbandingan TOR (Turn Over Ratio) dan Ratio Nilai Stock terhadap Persediaan Terpakai sebelum dan setelah penerapan Sistem Perencanaan Metode Konsumsi dengan peramalan 1 dan 3 bulan

\begin{tabular}{ccccccc}
\hline NO & $\begin{array}{c}\text { Omzet } \\
\text { Persediaan } \\
\text { Setahun (Rp) }\end{array}$ & $\begin{array}{c}\text { stok } \\
\text { akhir tahun } \\
(\mathbf{R p})\end{array}$ & $\begin{array}{c}\text { Persediaan } \\
\text { Terpakai (Rp) }\end{array}$ & TOR & $\begin{array}{c}\text { Ratio Stok } \\
\text { terhadap } \\
\text { Persediaan } \\
\text { Terpakai }\end{array}$ & Ket \\
\hline \hline 1. & $3,420,754,133$ & $483,139,150$ & $2,937,614,983$ & 7.08 & $1: 6$ & $\begin{array}{c}\text { Data Riil } \\
\text { LT. } 1\end{array}$ \\
2. & $3,642,856,655$ & $351,450,546$ & $3,291,406,108$ & 10.37 & $1: 9$ & bulan \\
3. & 4,111,249,050 & $351,450,546$ & $3,759,798,503$ & 11.70 & $1: 10$ & LT. 3 \\
bulan
\end{tabular}

